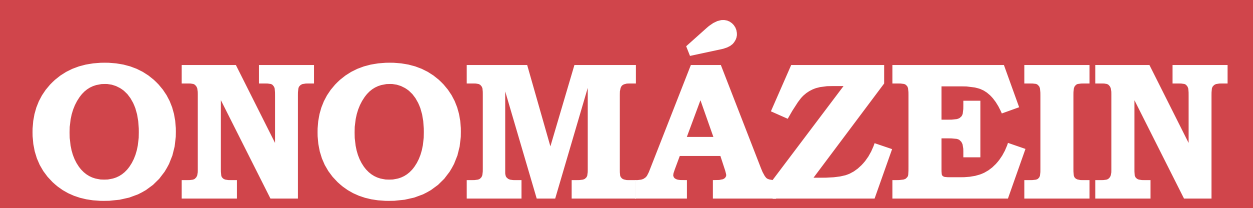

Revista semestral de lingüística, filología y traducción
PONTIFICIA UNIVERSIDAD CATÓLICA DE CHILE FACULTAD DE LETRAS

\title{
Sixteenth century punctuation in the "Booke of soueraigne medicines"1
}

\author{
Francisco Alonso Almeida \\ Universidad de Las Palmas de Gran Canaria \\ España
}

\section{Ivalla Ortega Barrera}

Universidad de Las Palmas de Gran Canaria España

ONOMÁZEIN 30 (diciembre de 2014): 146-168

DOI: 10.7764/onomazein.30.9

Francisco Alonso Almeida: Departamento de Filología Moderna, Instituto Universitario para el Desarrollo Tecnológico y la Innovación en las Comunicaciones (IDeTIC), Universidad de Las Palmas de Gran Canaria, España. | Correo electrónico:falonso@dfm.ulpgc.es

Ivalla Ortega Barrera: Departamento de Filología Moderna, Instituto Universitario para el Desarrollo Tecnológico y la Innovación en las Comunicaciones (IDeTIC), Universidad de Las Palmas de Gran Canaria, España. | Correo electrónico: iortega@dfm.ulpgc.es 


\section{Abstract}

The present paper seeks to explore the uses of punctuation symbols in the "Booke of soueraigne medicines" (ca. 1550) written by John de Feckenham (1515 - ca. 1584). Sixteenth century punctuation in scientific manuscripts has been often the cinderella of this type of studies, since scholars have been generally interested in literary printed material and grammar books of the period (Howard, 1930; Ong, 1944; McKenzie, 1959; Salmon, 1962 and 1988; Clemens and Graham, 2007). In our analysis of the data, we will apply Lucas's (1971) notion of sense-units in order to avoid imposing our modern view of syntax on the texts under scrutiny. Our methodological approach will also combine an analysis of genre variables in the texts within Feckenham's volume, since earlier studies have shown that the generic structure of the texts is strongly linked to what Lucas has labelled as structural and interpretative-expository punctuation. We conclude that the uses of punctuation marks are clear and systematic for one specific text and scribe. This study will benefit later critical editions of this and similar texts.

Keywords: punctuation; early modern English; manuscripts; sense-units; rhetorics; genre; text-type. 


\section{Introduction}

Before the invention and consolidation of the printing press, scribes used punctuation sparingly, each applying symbols in a very personal way. For this reason, some scholars have considered scribal punctuation to be unpredictable and arbitrary (Petti, 1977: 25; Parkes, 1978 138-139). Far from this assumption, we will show that punctuation is extremely coherent and systematic within the boundaries of one sole piece of text, as seen in the text of "Booke of soueraigne medicines" (ca. 1550) handwritten by John de Feckenham (1515 - ca. 1584). Earlier studies have revealed that medieval scribes used symbols for a variety of functions, and, even when the intended purpose of their usage clashed, scribes tended to attribute a special, distinguishable function to each one (Alonso-Almeida, 2002; Ca Ile-Martín, 2004; Calle-Martín and Miranda-García, 2005; Esteban-Segura, 2009; Marqués-Aguado, 2009 and 2011). Consequently, studies on Medieval and Renaissance textual segmentation carry out analyses of the texts based on single texts to unveil specific scribal use of punctuation. Generalisations in this respect are not always possible because systems of punctuation are often idiosyncratic

The Renaissance punctuation of literary texts has received some editorial attention (Fries, 1925; Graham-White, 1982; Clemens and Graham, 2007), whereas the study of punctuation in technical and scientific texts has not Recently, Calle-Martín and Miranda-García (2008) have brought to our attention the paucity of critical literature in this respect. In their paper, the authors analyse and describe punctuation in legal documents found in G.U.L. MS Hunter 3 (S.1.3) and conclude that symbols are employed with structural or rhetorical definite aims. In our study, we have looked at a similar issue, but in a completely different field. Our text belongs to the medical register and consists of more than seven hundred recipes written by the same hand. Space limitations prevent us from considering other hands in this paper. In contrast to medieval medical texts, the punctuation of which has been the focus of some research projects, to our knowledge no studies have used Renaissance medical manuscripts to a similar end.

This said, our objective is both to detect and to describe punctuation symbols in the sixteenth-century medical recipes of John de Feckenham, henceforward $\mathrm{H}^{2}$. This analysis draws on previous studies by Lucas (1971), Görlach (1992), Alonso-Almeida (2002), and Calle-Martín (2004). The theoretical framework is specifically based on the works by Lucas (1971) and Görlach (1992), reconciling both the structural and the reading uses of punctuation marks. This model is made up of two steps. One includes outlining the generic structure of the texts (Hasan, 1985, and Eggins, 1994) ${ }^{3}$ under scrutiny, and the other involves revealing the intentions behind the use of each mark.

The structure of the paper is as follows. Section 2 offers a description of the data under analysis. The following section outlines a description of the theoretical framework followed in the analysis of the punctuation symbols in $\mathrm{H}$. Section 4 presents the results and the discussion of findings, and finally the conclusions are given.

\section{Description of data}

The data we shall analyse consist of the recipes in G.U.L. Hunter 93 (T.4.10), which contains 739 texts written by ten scribes in English with

2 The main author of this volume is John de Feckenham, née John Howman; he was born in Worcestershire and died in Wisbech, Cambridgeshire. He studied in Oxford where he was chaplain to Bishop Edmund Bonner, and later he was appointed Abbot of Westminster. He opposed Protestantism during the reign of Edward VI, and for this reason he was sent to prison until Mary I released him. During Elizabeth I's reign, he was again imprisoned in the Tower of London for his religious beliefs in 1560 until the end of his days.

3 See section 2.1, below, for a description of the term "generic structure". 
a few Latin additions. The majority of these recipes are the work of John de Feckenham, and they will be the ones under examination. The complete manuscript book has been transcribed by Ortega-Barrera (2005), and presents 301 pages of running text with remedies separated by means of titles. Each page contains around 26 lines in one single column. The contents of the recipes are miscellaneous ranging from remedies for the patient's head down to his or her feet in the traditional de-capite-ad-pedem arrangement. Some of them offer instructions for the preparation of medicinal waters and other general preparations to be stored for future use, and others give information about therapeutic baths and medical advice to keep readers in good health. The sources for this compilation of recipes are varied, but they are mostly medieval.

\subsection{Textual genres in Hunter 93}

As we have mentioned earlier in this paper, a prior analysis of the recipes from a genre perspective helps to identify the uses of punctuation marks, because the generic structure of texts gives us an idea of the author's intended syntactic segmentation, and this may shed light on the uses of some marks that, at first glance, appear questionable. Furthermore, this may enable us to predict the presence of certain symbols within the texts. This happens at the division points between genre sections or stages, for instance, to mark off either the end of a section or the beginning of a new one. This approach avoids interpreting original syntactic patterns from the perspective of the modern reader, and thereby minimizes the possibility of forcing particular readings of the texts. In $\mathrm{H}$, we find the following genres, which will be described in the subsequent subsections: (a) recipe and (b) advice.

Genre and text types are two related concepts that have created some confusion among scholars (Carroll et al., 2003: 8; Taavitsainen, 2001a: 139) to the extent that genre and text types have been used indistinctively in the de- scription of texts (Görlach, 1992; Biber, 1988). Our definition of genre follows Martin (1984: 25), who claims that it is "a staged, goal-oriented, purposeful activity in which speakers engage as members of our culture". Hasan (1985: 64) and Eggins (1994: 41) have described the stage organisation of texts into generic structure potential and actual generic potential. The first one offers all the possible stages of a particular genre, whereas the second one relates to the specific stages selected in an authentic example.

The main difference between genre and text type is that the former is externally and culturally defined, and the latter is internally and linguistically defined. In this respect, Biber (1988: 170) argues that "genre categories are determined on the basis of external criteria relating to the speaker's purpose and topic; they are assigned on the basis of use rather than on the basis of form". In his own words, text type refers to "grouping of texts that are similar with respect to their linguistic form, irrespective of genre categories". Although there are many text-type classifications, in this paper we follow Werlich's (1976) taxonomy based on linguistic variables currently associated to each text-type. Following his taxonomy, there are five different text types: description, narration, exposition, argumentation, and instruction. Recipes, we will show, mainly present instructive text-types.

\subsubsection{The recipe as a genre}

Recipes have been the focus of several studies from a historical perspective, especially those dating as medieval (Stannard, 1982; Hunt, 1990; Alonso-Almeida, 1998-1999 and 2002; Carroll, 1999; Taavitsainen, 2001b). Renaissance recipes have not received the same amount of scholarly attention and critical analysis, though. For the sake of clarity, we will concentrate on the excerpt below taken from our corpus for a description of Renaissance recipes (abbreviations in examples have been silently expanded; rest of text as in the original unless otherwise stated): 
(1) [A good Medicine for a Man that is -

bruysed in his Bones, with staff, fall or

cold./]TITLE

[Take hearbe grace called Rewe, with Hemlock, Ground=

=sell, Chickweed, Smallage, of every one a handfull,]INGREDIENTS. [and

breake them Between thy hands, and seeth them with

stale or vryne, the quantitie of a Pottle, and with

a pound of Sheeps Tallow; and when thou seest

the hearbes wax yellow, take wheat Branne, and

cast into the Panne, and make it Plasterwise,] preparation $[$ [

lay it to the place diuers tymes,]Applicationi. [and when thou

shalt change it, take stale and putt in the Panne

to the same hearbes, and boyle it againe,] PREPARATIOn2 [and lay it

to the sore often till it bee whole,]APPLICATION2 [for it will

heale by Gods grace./] EFFICACy (24)

This example shows all possible stages in a recipe. The generic structure potential and the actual generic structure are very similar, as shown in the patterns below; the circumflex symbol in this diagrammatic representation indicates that one stage compulsorily follows the other, whereas the asterisk is used to show that the order of the stages may vary:

generic structure potential

$($ IITLE) ^ INGREDIENTS * (PREPARATION) * (application) * (STORAGE) * (EFFICACY)

actual generic structure

$\mathrm{TT}^{\wedge} \mathrm{I}^{\wedge} \mathrm{P} \mathrm{I}^{\wedge} \mathrm{A} \mathrm{I}^{\wedge} \mathrm{P} 2{ }^{\wedge} \mathrm{A} 2{ }^{\wedge} \mathrm{E}$

The function of each stage is briefly summarised, as follows: (a) the tr stage is used to indicate what the recipe is good for, and also to mark the beginning of the recipe; (b) the I section contains the list of ingredients needed; (c) the p stage offers guidance as to how ingredients should be combined; (d) the a section shows how to administer the finished product to the patient; (e) the s section offers instructions on how the product must be stored for future use, and, finally, (f) the E section describes the expected remedy results.

As pointed out before, the prevalent text type is instructive, and the linguistic features strongly associated with this text type are imperative forms (take, breake, seeth, cast, make, lay, putt, boyle) and time expressions (when, and, often). The following lexical groups signal the topic of the texts: (a) medical terms (anatomy, diseases and related): medicine, bruysed, bones, vryne, sore, heale; (b) plant names: rewe, hemlock, groundsell, chickweed, smallage; (c) culinary and related terms: vessel, earthen pott, Pewter sawcer, pottle, morter, eggs.

Generic stages in the recipes in $\mathrm{H}$ can be identified by a set of morphological, lexical and syntactic configurations, which are fairly regular in recipes of a given culture. Table 1 illustrates the relationship between genre, text type and language.

\subsubsection{Advice as a genre}

Advice as a genre differs from recipes in that advice is intended to offer an opinion or recommendation to ensure good health, while recipes contain instructions to restore health. Advice has been often confused, and so they have been analysed as one type of recipe. Notwithstanding, Taavitsainen (2001b) and Ortega-Barrera (2009) have openly argued for the independent status of the advice genre. Example (2) is an instance of an advice text in G.U.L. MS Hunter 93. 


\section{TABLE 1}

Lexicogrammatical choices and content organisation in $\mathrm{H}$

\begin{tabular}{|c|c|c|c|c|c|}
\hline \multirow[b]{2}{*}{$\begin{array}{l}\text { GENERIC } \\
\text { STAGE }\end{array}$} & \multicolumn{4}{|c|}{ LANGUAGE } & \multirow[b]{2}{*}{ EXAMPLES } \\
\hline & VERB FORMS & LEXIS & CONNECTORS & $\begin{array}{c}\text { OTHER } \\
\text { LANGUAGE } \\
\text { STRUCTURES }\end{array}$ & \\
\hline TITLE & $\begin{array}{l}\text { infinitive of } \\
\text { purpose }\end{array}$ & $\begin{array}{l}\text { 1. disease } \\
\text { 2. anatomy }\end{array}$ & & $\begin{array}{l}\text { relative clauses } \\
\text { anaphoric } \\
\text { devices }\end{array}$ & $\begin{array}{l}\text { A good powder to helpe one } \\
\text { that hath Collica passio (52) }\end{array}$ \\
\hline INGREDIENTS & imperative & $\begin{array}{l}\text { 1. botany } \\
\text { 2. weight }\end{array}$ & And & $\begin{array}{l}\text { participial } \\
\text { clauses }\end{array}$ & $\begin{array}{l}\text { Take Anyseeds, ffennell } \\
\text { seeds and... (52) }\end{array}$ \\
\hline PREPARATION & imperative & $\begin{array}{l}\text { 1. botany } \\
\text { 2. culinary verbs } \\
\text { 3. weight } \\
\text { references }\end{array}$ & $\begin{array}{l}\text { And } \\
\text { When }\end{array}$ & & $\begin{array}{l}\text { and stampe them right small } \\
\text { in a Morter and temper } \\
\text { them with vinegre (143) }\end{array}$ \\
\hline APPLICATION & $\begin{array}{l}\text { imperative \& } \\
\text { coercive verbs }\end{array}$ & $\begin{array}{l}\text { 1. anatomy } \\
\text { 2. finished } \\
\text { products }\end{array}$ & $\begin{array}{l}\text { And } \\
\text { Till }\end{array}$ & & $\begin{array}{l}\text { and lett the Patient putt } \\
\text { a spoonefull at once } \\
\text { into his mouth (116) }\end{array}$ \\
\hline EFFICACY & future & $\begin{array}{l}\text { 1. words related } \\
\text { to healing faith }\end{array}$ & For & adverbials & $\begin{array}{l}\text { for it will destroy it by } \\
\text { Gods grace. (186-7) }\end{array}$ \\
\hline
\end{tabular}

(2) [III for the sight./] TITLE

[To studdy after meat, and wynes, Onyons, Leekes and Lettice; too suddaine going after meat, wynds, hott Ayre, and cold Ayre, Dronkennesse, Gluttonie, Milke, Cheese, much beholding of bright things, and aswell redd things as white, Musterd, much sleepe after meat, too much walking after meat, and too much letting of Blood, Colewortes, Incontinencie, fire, dust, too much weeping, and ouermuch watching./] RECOMMENDATIONS OR DIRECTIONS (84)

In this example, the author offers information on how to maintain good eyesight by avoiding things and actions that would harm it. The advice text divides generically into the following stages: (a) title (TT) indicating the contents of the text; (b) introductory information (InI), which is generally intended to give an idea of what the text is about, in the absence of a title; (c) recommendations or directions stage (RoD), which aims to give a series of indications to be followed or to be avoided to ensure good health, and, finally, (d) evaluation or statement of efficacy (E), which gives the result or the consequence of following the recommendations.
There is not one single instance of advice in $\mathrm{H}$ where all these stages are present. Based on the analysis of a corpus of Middle and early Modern English advice texts, Ortega-Barrera (2009: 44) outlines the generic structure potential of this genre, thus: $(T T)^{\wedge}(I n I) \wedge(R o D) \wedge(E)$. The application of this potential to the instance in (2), above, reveals that the actual generic structure is $T T \wedge$ RoD. The TT is characterised by the presence of an adjective plus a purpose phrase introduced by for, i.e. for the sight. The RoD stage often contains a sequence of noun or verb phrases followed by a for-purpose or an infinitive of purpose. In (2), the section begins with an infinitive 
of purpose followed by noun phrases: To studdy after meat, and wynes. The rest of the noun phrases given in this text do not present an infinitive structure. The noun phrases are realised either by nouns, much sleepe after meat, or nominalizations, too much walking after meat.

As pointed out, the other two stages in the generic potential structure, namely InI and $\mathrm{E}$, are not present in this instance. Examples of the former take the shape of hedges or stance expressions that occasionally introduce the topic of the text they are in, and at other times aim to mark the transition from a previous recipe: No seson of the yere is better than he, neyther profitabler to letting of blode (56), In pis seson pu hast need [...] (f. 6v), And pe bettir for helth and digestion (f. 8), For whi in slepe many superfluytees ben withholde therfor [...] (f. 16). The E stage is normally a simple sentence whose verb appears in the present, as in and it maketh your eyes well to digest (84). This example is included in an advice text for good sight.

\subsection{Punctuation symbols in $\mathbf{H}$}

The symbols used in $\mathrm{H}$ are the following: (a) point, (b) comma, (c) semicolon, (d) colon, (e) parenthesis, (f) hyphen, (g) virgule, (h) paragraph, and (i) asterisk. The point (.), the comma (), the colon (:), and the semicolon (;) are placed on the line of writing, and they resemble their modern counterparts in form. The hyphen (-) is above the line of writing, and it can be single or double (=). The virgule (/) is a slanting bar or slash. It sometimes appears in combination with the point either preceding it (/.) or following it (./) in what is known as perioslash. The paragraph mark (9) is very similar to a majuscule letter $\langle p\rangle$ with the lobe to the left of the shank. The lobe is completely black and above the lobe a line horizontal to the line of writing extends towards the right. A point always accompanies this mark on its right. The asterisk (*) has a starry shape consisting of three strokes; two of them are crossed in the form of the letter $\langle x\rangle$, and the third crosses the $\langle x\rangle$ shape medially and horizontally to the line of writing. The paragraph mark and the asterisk normally appear in the margins of the text. In figure 1 , we offer the percentages of occurrence of punctuation signs in the manuscript. As shown in this figure, the use of the comma really outnumbers the use of any other symbols. The percentages in figure 1 and table 2, below, are based on raw data concerning the occurrences of these symbols in $\mathrm{H}$.

\section{FIGURE 1}

Occurrences of symbols (percentages)

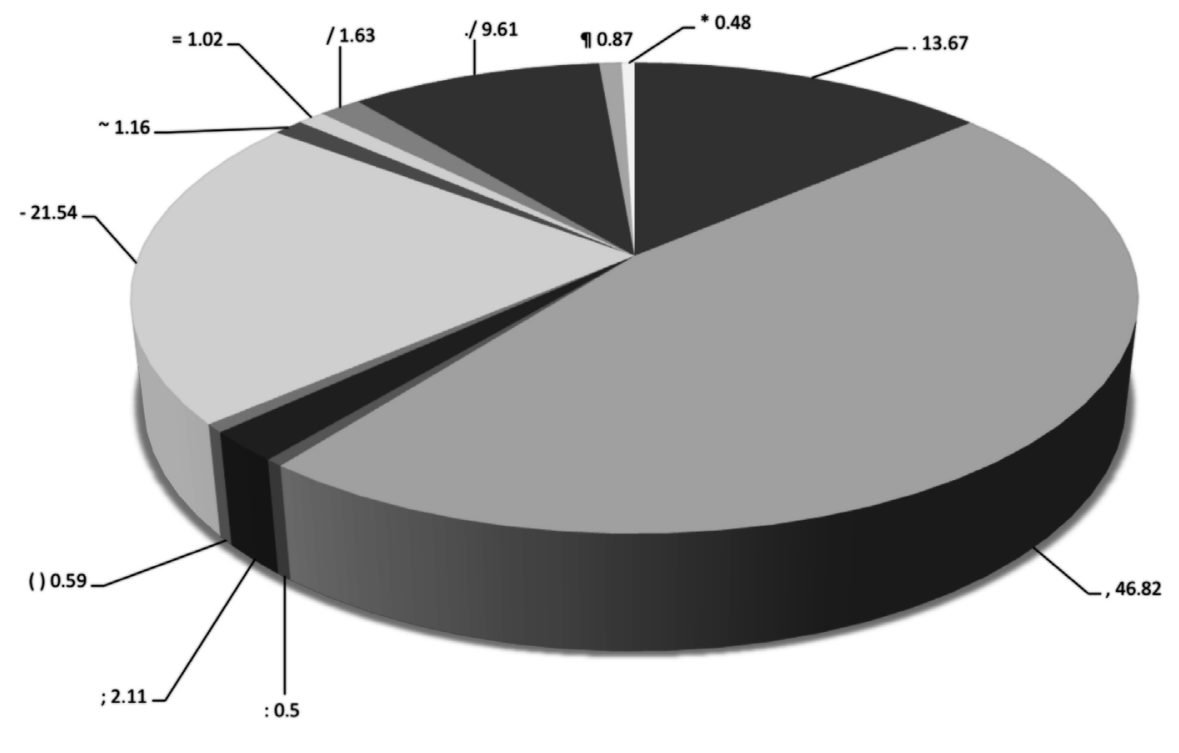


Table 2 shows the percentages of both the presence and the absence of symbols in the work of Feckenham, except for the paragraph mark and the asterisk, which are only used in marginal notes. The slash also includes the occurrences of the perioslash.

\section{TABLE 2}

Summary of the functions of each punctuation symbol in $\mathrm{H}$, including the percentages of the presence $(P)$ and absence (A) of each symbol ${ }^{4}$

\begin{tabular}{|c|c|c|c|c|c|c|c|c|c|c|c|c|c|c|c|c|}
\hline & \multicolumn{2}{|c|}{. } & \multicolumn{2}{|c|}{, } & \multicolumn{2}{|c|}{; } & \multicolumn{2}{|c|}{ : } & \multicolumn{2}{|c|}{ (1) } & & \multicolumn{2}{|c|}{$=$} & \multicolumn{2}{|c|}{ I } \\
\hline & $\mathbf{P}$ & A & $\mathbf{P}$ & A & $\mathbf{P}$ & A & $\mathbf{P}$ & A & P & A & $\mathbf{P}$ & A & $\mathbf{P}$ & A & $\mathbf{P}$ & A \\
\hline 1 & 5.22 & 3.27 & 22 & 9.92 & 0.85 & 1.09 & 0.02 & 1.09 & & & & & & & 9.26 & 3.94 \\
\hline 2 & 4.6 & 3.14 & & & & & 0.06 & & & & & & & & & \\
\hline 3 & 0.36 & 0.22 & 0.28 & 0.04 & & & 0.02 & & 0.19 & & & & & & & \\
\hline 4 & & & 15.7 & 4.7 & & & & & & & & & & & $\begin{array}{c}1 \\
\text { case }\end{array}$ & \\
\hline 5 & & & 1.53 & 0.35 & & & & & & & & & & & & \\
\hline 6 & & & 0.72 & & 0.17 & & & & & & & & & & & \\
\hline 7 & & & 6.59 & 3.04 & & & & & & & & & & & & \\
\hline 8 & & & & & 0.77 & & & & & & & & & & & \\
\hline 9 & & & & & 0.22 & & & & & & & & & & & \\
\hline 10 & & & & & & & 0.04 & & & & & & & & 1.86 & 0.87 \\
\hline 11 & & & & & & & & & 0.40 & & & & & & & \\
\hline 12 & & & & & & & & & & & 21.4 & 42.8 & & & 0.12 & \\
\hline 13 & & & & & & & & & & & 0.14 & 1.48 & & & & \\
\hline 14 & 2.39 & 17.7 & & & & & & & & & & & & & & \\
\hline 15 & 1.10 & 5.15 & & & & & 0.01 & & & & & & & & & \\
\hline 16 & & & & & & & 0.35 & & & & & & & & & \\
\hline 17 & & & & & & & & & & & & & 1.02 & & & \\
\hline 18 & & & & & 0.10 & & & & & & & & & & & \\
\hline
\end{tabular}

4 Key to table: 1 . to separate sections; 2 . recipe end; 3 . to introduce metatextual comments; 4 . to associate phrases; 5 . to enumerate; 6 . fronting of phrases; 7 . to clarify meaning; 8 . to associate parts in a section; 9 . to indicate the end of a list; 10. to introduce index section letters; 11 . to signal appositions; 12. line filler; 13 . to make compounds; 14. to accompany numbers; 15 . to indicate abbreviation; 16. to signal measure and time units; 17. to join two parts of a word given; 18. to convey adversative meaning. 
As seen in table 2, the figures for absence symbols do not show remarkable differences in general, except for some uses of the point, the semicolon, the colon, and the hyphen. Of these, the most significant P/A alternation is found in the use of the point and the hyphen. The point does not seem to be applied consistently to mark off the recipe end, to show the presence of numbers and to indicate abbreviations. The tendency to avoid the point with numbers is noteworthy, and is a function that was well-rooted in the medieval manuscript writing tradition, but bound to disappear later on. The hyphen is unevenly used as a line filler, and frequency indicates the tendency of this function of the hyphen to fall into disuse. As a whole, the absence of these symbols where expected suggests an inconsistency of scribal usage in applying punctuation, especially in those cases where syntax would not require the marking of segmentation or association of units in sentences during later periods of English.

\section{Theoretical framework for the study of punctuation}

The present section shows the model used in the description and interpretation of punctuation symbols in $\mathrm{H}$. This framework follows from Lucas's analysis of punctuation in Capgrave's Chronicle, which enables the uses of marks to be identified efficiently (Lucas, 1971: 3). This model bridges the gap between the two functions of punctuation: that of showing the structure of the text and that of indicating reading pauses. Lucas (1971) divides punctuation according to description of category-type into (a) intentional and (b) functional. The intentional category comprises (a1) structural and (a2) interpretative functions. This interpretative function is further subdivided into (a2.a) expository and (a2.b) elocutionary. From the perspective of function, the category of structural punctuation divides into a further two sub-sections, namely (b1) grammatical, which separates sense-units, and (b2) notional, which associates structurally independent (groups of) sense-units. These two functional categories are not mutually exclusive.

A sense-unit is equivalent to a complete sentence, i.e. subject plus predicate. Sometimes, a phrase may be also considered a sense-unit, as in coordinated sequences in which the verb phrase is not repeated: Take a plate and a fork. A reanalysis of this sentence would read: Take a plate and take a fork. A conjunction or any other discourse marker, or punctuation mark indicates the relationship held between sense-units in a particular sequence. The following example from Lucas (1971) shows the structural function of punctuation:

(3) [the Earl of Westmoreland]... inqwyred why pis puple was gadered. \& pe archbishop answered ageyn. (Lucas, 1971: 18)

In this example, the boundary between the grammatical and the notional use of the point is very subtle. We may think that the function of the point is grammatical because it is separating two sense-units. However, note that the senseunit after the point refers to the answer to the indirect question given earlier, and so the function of this symbol could also be notional and not exclusively grammatical. In this case, the point associates two related strings of language.

The examples below illustrate the interpretative use of punctuation marks:

(4) a. Pat men shul of pité gyue hem good. long aftir pe fadir of on of hem cam to London. (Lucas, 1971: 23) b. In pe ix zere of pis kyng John Wyclef pe orgon of pe deuel. pe enmy of pe cherch. pe confusion of men. pe $y d o l$ of heresie. pe mereour' of ypocresie. pe norcher of scisme. be pe rithful dome of God was smet with a horibil paralsie. (Lucas, 1971: 19) 
Whereas the structural function refers to how the information is organised in the text, the interpretative function refers to the author's attitude towards what he has written. Thus, the expository interpretative category shows the author's desire to clarify the sense of the text, and the elocutionary interpretative punctuation indicates the author's desire to indicate how the text should be read aloud. These two categories are not mutually exclusive in effect. In example (4a), the function of the point is the disambiguation of alternative readings of the text. In these readings, the word good has an attributive function complementing the verb gyue, or it acts as a modifier to long. With the point, the author manifests his intention to indicate that good is the last word of the sense-unit. Therefore, its primary function is expository. In the second example (4b), the intention of the writer is not only that of associating noun phrases, he also appears to specify reading pauses so that the reader of the text or the audience "would weigh the material more carefully” (Lucas, 1971: 19).

\section{Analysis and discussion of findings (by symbol)}

In our analysis, we shall study the uses of each punctuation mark on its own in the order presented in section 2.2 in terms of the theoretical framework described above, in section 3. For each use, we will give examples from the manu- script. The descriptions are always for the main hand of $\mathrm{H}$. Subsequently, we offer a summary of punctuation practice in $\mathrm{H}$ to show visually how the punctuation symbols function.

\subsection{The period or point}

The point is one of the commonest punctuation marks in the text of $\mathrm{H}$. It has an array of functions, but they mainly fall into the notional and grammatical categories within Lucas's (1971) taxonomy. The point in $\mathrm{H}$ has two positions with respect to the line of writing: one is exactly on the line, and the other one is between two lines. There is no specialisation in the syntactic or rhetorical function of the point in terms of its position. We have observed the following functions of the point: (a) to separate sections within the text, (b) to indicate the end of the remedy, (c) to introduce a metatextual comment, d) to show abbreviation, and, finally, (e) after numbers. What follows is a description of each of these functions.

One recurrent function of the point in $\mathrm{H}$ is to separate sections within the text, especially the title, and the end of the recipe. As we have shown above in section 2.1, the recipe and the advice texts have a particular structure that we have divided into a set of generic stages. These stages are marked off by points preceding them, as in the examples below (we offer manuscript pages in brackets):

(5) a. A speciall good water for the Eyes. Take a new layd Egg [...] (77)

b. A good Laxatiue for a Child. Take iij handfulls of Vyoletts [...] (137)

c. A Gargarisme for the fflegme./ Take a quantitie of Endive water, and

asmuch hony - Suckle water, a good spoonefull of pure Musterd, a -

spoonefull of hony, two spoonefulls of vinegre [...] and lett the Patient putt

a spoonefull at once -into his mouth, and hold his head vpward, and wash -

his throat therewith, and it shall make him avoyd much fflegme. Lett him

take thereof, as often, as hee shall thinke good./ (115-6)

In the first two examples, the point is used to separate the title of the recipes from the ingredients section. This section begins with the formulaic Take that normally signals the beginning of this stage in recipes. In the last example (5c), the preparation and the application stages are separated off by means of the point.

A variety of ways are used to show the end of the recipe in $\mathrm{H}$, one of which is the period, as seen in this instance: 
(6) Take the Blood of an Oxe for a man, and for a woman the blood of a Cowe, and annoynt thy face therewith. (120)

This grammatical use of the point allows us to posit that Renaissance scribes had an idea of this symbol as marking a strong division. Sometimes the recipe end is emphasised by means of an efficacy comment in the form of the tag phrases probatum and proued. In this case, the point signals the start of a new section rather than the end of the remedy. Note that, in the second of the following two examples, the point separates the two efficacy statements. The first one refers to the relationship between medicine and religious faith, whereas the second asserts the efficacy of the remedy through experimentation, i.e. a more "scientific" approach.
(7) a. ffor an extreame Cold./
[...] and keepe it for-
vse; Take a spoonefull thereof often. Probatum est per
D: ff: (69)
b. ffor the same./
[...] and the sick shall fynd ease thereby
by Gods grace. Proued by mr Bauker./ (16)

Another function of the point is to introduce a metatextual comment, in which the reader is instructed to read back or forward in the text for similar therapeutic information:

(8) a. [...] and it stancheth blood well. Of this matter more at large before pag. where wee have entreated of Bleeding and how the same must bee stayed, and stopped./ (205)

b. [...] fry the luyce thereof in Butter, and drinke it warme. Of this more pag. 40 / (10)

In these two examples, the cross-references have been signalled by the use of a point. In the first one (8a), the remedy is for haemorrhages, and so the reader is given a page for further reference on that topic within the book. The second one (8b) deals with a recipe for venom, and a similar remedy is found later in the book, i.e. For byting of any venemous Beast. In this remedy on page 40, we find another reference to the one under discussion here, also preceded by a point: of this before pag. 10.

A final use of the point in $\mathrm{H}$ is to indicate $a b$ - breviations and page numbers. The commonest abbreviations are: $v^{e}$., $C^{o}$., \&Cs., $D^{r}$., $W^{\text {th }}$, fol. that stand for vide, capitulo, et ceteris, Doctor, with, and folio, respectively. A detailed examination of the abbreviations in the text of $\mathrm{H}$ reveals that the author writes, for instance, either Dr. or Dr, regardless of whether the last consonant of the reduced forms coincides with the last consonant of the full forms. By contrast with present day English, there is no distinction between the use of the point in abbreviations. Even if the abbreviated word finishes with the same letter as its full form, the point is used. As for page numbers, some of them are followed by a period: 123., 124., 125., etc.

\subsection{The comma}

The comma is by far the commonest means of registering punctuation in $\mathrm{H}$. This punctuation symbol was not used in England before the sixteenth century (Calle-Martín and Miranda-García, 2008). In general, the uses of this sign are patently different from its modern descendant. In the text of $H$, the shape of the comma seems to resemble a small short curved virgule 
on the line of writing, and its functions are varied. Calle-Martín and Miranda-García (2008: 367) argue that the comma in their text, i.e. Glasgow University Library, MS Hunter 3, is often used for short pauses.

In the case of $\mathrm{H}$, the main function of the comma is not to indicate a short pause. Rather, it is used with a strong grammatical function to separate sections within the texts. As we shall see, the pause thus indicated is not as long as that shown by a point, a slash or a perioslash, but it is not as short as in present day English. In fact, there are cases in which the comma matches the functions and distributions of a point, but it nev- er appears in the place of a slash or perioslash in those cases where they appear at the end of the texts. Having clarified these aspects, we can state that the functions of the comma are (a) to mark off sections in genres, (b) to associate clauses and phrases within a specific sense-unit, (c) to enumerate phrases, (d) to show the fronting of adverbial clauses, (e) to clarify meaning, and ( $f$ ) to introduce a metatextual comment or stance.

To mark off stages in genres and associate clauses within each stage. The comma is recurrently used to indicate the division of sections in the texts in $\mathrm{H}$, as seen in the example below (underlining shows specific examples):

(9) A Medicine for an Ache, or shrinking

of Synewes. \&c.

Take the Tenderings of Rosemary, and March and Mallowes of Even porcions, as you can guesse ${ }_{2}$ gatheryour hearbes when they bee drye from rayne and dewe, $\boldsymbol{L}_{\mathbf{2}}$ pound them in a Morter very small $\mathrm{L}_{2}$ Then take May Butter well clarified, and putt it to the hearbes, and mingle it in a close Vessell and lett it stand four dayes, then sett it over the fire, and lett it seeth, till the strength of the hearbes bee gone, then take a little of it in a spoone, and lett it dropp vpon the Nayle, and if it bee greene as the Emerauld, it is perfect, and then putt it in an Earthen pott, and when thou will occupie it, you must warme it./ (6)

In (9), those commas dividing sections appear in bold type and underlined. Sections are here considered as sense-units (Lucas, 1971), since each one has a distinctive function within the general scheme of the recipe. Besides, this division of sections as sense-units is backed by recurrent linguistic and thematic strategies. The first comma separates the ingredients sections from the preparation section, which begins with the imperative verb pound. In the same vein, the second comma shows the end of the prepara- tion section and the beginning of storage while the last underlined comma signals the start of the application section. The commas underlined show the different steps within the different sections to prepare the remedy. The use of the comma is grammatical because it helps to structure the text, but also notional because it indicates the reader how phrases and clauses, i.e. senseunits, combine. Diagrammatically, the sections are outlined as follows:

I Take... gather

P pound, Then take, and mingle, and lett, then sett, then take, and 
then putt, and when thou will occupie

To enumerate items in a list or phrases in a sense-unit. The comma's function is to link formally similar sense-units (i.e. noun phrases). By using the comma, the scribe avoids overusing paratactic particles to associate sense-units, although the combined use of the comma and the ampersand (or and) is observed in the text with the same function, as in the example above. In this instance the sense-units associated are not clauses, but phrases of a non-verbal nature. Consider now the following instances:

(10) III for the sight./

To studdy after meat, and wynes, Onyons, Leeks and Lettice; too suddaine going after meat, wynds, hott Ayre, and cold Ayre, Dronkennesse, Gluttonie, Milke, Cheese, much beholding of bright things, and aswell redd things as white, Musterd, much sleepe after meat, too much walking after meat, and too much weeping, and ouermuch watching./ (84)

The comma here has a structural function. In this piece of advice, the writer combines the use of both the comma and the semicolon to list a number of actions that are detrimental to one's eyesight. The comma is found after each noun phrase to associate nouns (wynds, ayre, dronkennesse, milke) and deverbal nouns (walking, weeping, watching). The semicolon, extensively covered below, seems to be used notionally to indicate that the nouns preceding it belong to the previous verbal phrase. This would be an expository use of the semicolon.

To show the fronting of an adverbial clause. The author in this case may be using the comma to front specific noun phrases or clauses in order to emphasize particular information. Thus, the function of this symbol here may be notional rather than grammatical, as in the examples below:

(11) a. when it is boyled enough, straine it through a Cloth into a Vessell. (62)

b. And if you can gett noe-

Winter Savory, take Tyme, and more of the Hopp./ (93)

In both cases, the commas underlined fulfil a notional function since they are associating the clauses introduced by when and if with their main clauses, which appear afterwards. The dislocated when in the first instance emphasizes a step in the preparation process, that is, the boiling of the product before straining the resulting liquid through a cloth. In other words, this dislocated clause implies a condition that is a necessary prerequisite for the performance of the step depicted in the main clause. In (1zb), the if-clause focuses on predictable information, that is, the lack of an ingredient and provides the context for the presentation of an alternative ingredient.

Besides indicating the fronting of an adverbial clause, the comma also signals the fronting of an adverbial phrase, as in For an Ache in the Back, a Soueraigne Medicine (8). In this example, the change in syntax is manifested by the use of the comma preceding the noun phrase on which the preceding prepositional phrase with for depends. As in the previous examples, left dislocation seeks to place the topic of interest, that is, what the recipe is for, first. 
To introduce appositions, clarifications, metatextual comments, and stance. Appositions, metatextual and stance expressions are often signalled by means of commas. Those commas may have either a notional or an expository value in discourse. Some examples are given below:

(12) a. A good Medicine for an Ague, bee it Quo=

tidian or Quartaine/. (14)

b. drinke the smallest Ale that you can gett, and if -

it bee not small, you must allay it with Barberry water -

or pure water, boyled. (17)

c. drinke

it warme, a little before the tyme that the fitt shall

come $e_{2}$ That is to say, when you shall perceive any

mynding. (14)

In our opinion, the function of the comma underlined in these examples could be either expository or elocutionary. Where it is expository, the comma aims at highlighting a particular piece of information not captured in the utterances given later. This new information is necessary either to completely understand the preceding message either by adding a particular aspect not mentioned before (bee it Quotidian or Quartaine, boyled) or by clarifying the meaning of the utterances (that is to say). It could be the case that the comma also has an elocutionary force, and the reader is compelled to slow his reading pace to process the additional information.

Another use of the comma related to clarification is to show relative clauses. As in present-day English, relative clauses are given between commas when they are non-restrictive, and without them when they are restrictive. consider the following examples:

(13) a. This Booke of soueraigne

Medicines against the most common and

knowne diseases [...]

collected by Doctor ffecknam late

Abbot of Westminster, \& that

«chiefly For those who [...]

〈have not allway<es the〉

<learned P<hisitians> (i)

b. Then Launce the Goomes betwixt the Teeth

which doe paine you. (2)

c. A Soueraigne Medicine for the Collique -

a stone, which will breake them both./ (53)

d. Take a quart of Malmsey, and a pennyworth of Commyn, and

viij Betony leaves that groweth on the land ( $p$. 74)

That and which are the most frequent relative pronouns in $\mathrm{H}$, and who only appears twice. All uses of who are restrictive, as in (13a). Which and that are preceded by a comma when the information given is additional and not necessary for identification. These are instances of non-re- strictive relative clauses. The only case in which a comma is used in a restrictive context is (13C), above. The function of the comma here is expository rather than notional, since it is indicating to the reader that the antecedent of the relativiser which is a Soueraigne Medicine and not a stone. 


\subsection{The semicolon}

The semicolon was first used in England in the fifteenth century, but despite the fact that it is older than the comma, its presence in $\mathrm{H}$ amounts to only $2 \%$ of the cases in which a punctuation mark is used. It is used in the following ways: (a) to separate sections, (b) to associate different parts within a section, (c) to show the end of a list, (d) to show fronting of adverbials, and (e) to show adversative meaning.

To separate sections. As we have seen with the period and the comma, the semicolon is used to signal the end of a section and the beginning of a new one. The function of this symbol here is grammatical, as it indicates the disassociation of two sense-units. In the example below, the beginning of a new efficacy stage is shown by the semicolon (underlining in the example is original).

(14) ffor the same./

Take asmuch fine lynnen Cloth, as will make a Suppo=

=sitary, being wropped round together Button wise, then

wett the same in the best Aquavitae, or Aquacomposita, \&

lett the Partie greived, convey the same into you're their

ffundament, and it will helpe them (God willing) -

within iij or iiij dressings; This is proved, and hath

holpen many that have been brought very lowe, and

reckoned past cure./ (96)

To associate the parts within a stage. The semicolon has both grammatical and notional functions here. Its grammatical function serves to show the different parts involved in a particular process, such as the combination of in-

gredients in the preparation stage, whereas its notional use associates these different parts as belonging to one same process. Very often, the semicolon precedes either then or and then.

(15) An Oyntment for Ach, and specially in all old Causes for the Collique or feeble stomack, for bruysing specially, for Botches, for Brests, for ffellons, for wounds, for all manner of old sores./ Take a Pottle of fyne meat Oyle Olive, of the best, boyle therein a Pottle or more of Angell parts, other =wise called Angell warts being not washed, but cleane striped from the Earth, stirr them allway [...] Then strayne out the Oyle, and take wax fine cleane Rozen, and Sheeps Tallow, or Sewett of a deere molten and purified, of each a pound, of ffrankinsence iij quarters of a pound well ground to powder; Then melt all with the fire, and putt them to the foresaid Oyle; Then take 5 . handfulls of Plantyne, iiij handfulls of shee holkes that hath a long stalke, soft leaves of Molyn, and white fflowers, iij handfulls of Celidone, iij handfulls of Woodbynd, and asmuch Smallage two handfulls of Elacampana [...] (155-6) 
To indicate the end of a list. After enumerating ingredients or actions in a process, a semicolon is frequently found to notionally indicate the end of the list. The following illustrates this function of the semicolon:

(16) a. The Receipt of Mynt water /

Take one Gallon of the best Spiritt of wyne, ij

Gallons of Sack, and infuse therein these spices foll= =owing, Cynamond one Ounce, Cloves, Nuttmeggs, ginger, large Mace, Long Pepper, of each halfe an ounce, Callamus, Gallangall, Cyperus, Cardamerus, of each three dramms; Beat all these together, and infuse them therein, the space of forty viij houres[...] Then distill it either in Limbeck, or glasse Body in drye Balmeum, soe long as there runeth any Spiritt./. In this Spiritt infuse these things following, Cynamon

[...] (149-50)

b. The vertue of the foresaid water is this. It comfor= =teth the Spiritts vitall, it helpeth inward diseases that come of cold, and against the shaking of the Palsey; It cureth the Contraccioum of Synewes; It helpeth the Concepcioum of women, it killeth thewormes within the Belly; It cureth the old Gowte, It helpeth the Toothach, it comforteth the Stomack; It cureth the old dropsie; It helpeth the Stonein the Bladder, and in the Reynes of the Back; It helpeth shortly a stincking Breath; And whosoeuer vseth the water now and then, and not too often, It preserved them in good likeing, and marvelously comforteth nature / (216)

In the first example, the semicolon is used to signal the end of the list of ingredients. The second example is more interesting in the sense that the list is made up of complete sentences that describe the benefits of a particular medicinal water. The semicolon is used differently here, as it is sometimes placed after a sentence, while on other occasions the semicolon appears after two or more sentences linked by means of a comma: It cureth the old Gowte, It helpeth the Toothach, it conforteth the Stomack; It cureth...
To introduce adversative meaning. The function of the semicolon is notional; the writer initiates adversative meaning with either and or but, and this is always indicated by means of this punctuation symbol. The comma, as already described above, also shares this role of the semicolon. Note that both punctuation marks are used with the same purpose in the first example (a), below (we have underlined the symbols of interest in this instance).

(17) a. Another for the same./

Take an old cleane lynnen Cloth and wett it well in vinegre, then burne it to powder, and take the powder thereof $f_{L}$ and if it bee a wound cast it therein, and it will stopp the Bleeding immediatly; But if - 
thy Nose bleed, then snuffe vpp the said powder into

thy Nose, and it shall stint bleeding / (30)

b. you must boyle all these

together, till it wax rugged in the Bottome; But -

for saving of the potts Bottome, you must stirr them

together./ (116)

To show the fronting of an adverbial clause. The semicolon indicates that the adverbial clause precedes the main clause in a given senseunit. This is exemplified in a recipe for bruises in the bones where the fronting of the adverbial and when thou seest is marked by this symbol: seeth them with stale or vryne, the quantititie of a Pottle, and with a pound of Sheeps Tallow[; And when thou seest the hearbes wax yellow, take wheat Branne, and cast it into the Panne (24).

\subsection{The colon}

The colon in $\mathrm{H}$ has different, mainly grammatical and notional, functions. The grammatical uses of the colon are (a) to separate sections and to give a new recipe in running text, and (b) to introduce index sections, while the notional uses are (a) to indicate measure and time expressions, (b) to signal a cross-reference comment, and (c) to show abbreviations. We will now describe each one in turn.

To separate sections and to give a new recipe in running text. A colon normally introduces the preparation section after the list of ingredients has been given. As can be seen in example (a) below, whenever the preparation stage is preceded by this punctuation symbol, an anaphoric referential device captures the meaning of the previous section in the recipe, i.e. these, in this instance. Example (b) shows how a colon divides two related recipes when they appear in running text without any visual device to mark the distinction between the two recipes

(18) a. ffor the Plague./

Take Bole Armoniake, a halfe penny waight, Sanguis draconis $j^{\mathrm{d}}$, terram Sigillatum jd, Setwall asmuch, ginger oleum: Take all these and bray them, and searce them small, and keepe the powder in a Box, [...] (174)

b. To helpe the Distillacioum of the Eyes./ Take Vervyne a little, and stampe it with the white of an Egg, and bynd the same with a little white fflax steeped therein when you goe to bedd, and it shall take away the watrishaies of them: Betony being in the like manner stamped and vsed, shall worke the like effect./ (83)

To signal index sections and page numbers. In $\mathrm{H}$, the index is arranged alphabetically, and a letter of the alphabet precedes each group of entries. That specific letter is followed by a colon, and sometimes this symbol is combined with a slash, thus: B: or B:\%. Throughout the recipe book, the index letter indicates group of recipes, and this is also marked by the use of the colon. This letter is centred on the line. Page numbers are rarely signalled by the colon, as in 2:, 3: and 4:, since the period should be preferred in this context, if any symbol is used.

To indicate measure and time expressions. This is by far the commonest function of the coIon in $\mathrm{H}$, and it resembles the use of the point in the medieval period with numerals. 
(19) A Medicine for the Measles./

[...] And thereto take drye ffiggs, and fflowers of Lentills mundified and made cleane Ana:3: and of the Gumme lacra dragance Ana: 301: lett them bee sodden in $v^{\text {li }}$ of water, vnto iiij: straine it, and putt therevnto 3: of Saffron [...] (148)

To show a cross-reference expression. Although the comma is more widely used in this context, the colon sometimes takes over this role and signals the addition of a metatextual comment, which itself represents a sense-unit, referring to other parts of the document where the reader may find related information to the disease and preparation in question.

(20) Also stampe two Cloves of Garlick, and lye it about thy Arme, on that side the Tooth aketh neer to thy hand, and it draweth away all the paine: Hereof wee have spoken before pag where wee have entreated of all kinds of Aches (235-6)

To show abbreviations. Abbreviations are also indicated by means of a colon. Abbreviations vary in form and may present apocopated forms or an initial. The point also shares this function.

(21) Probatum est per D: ff: (69)

\subsection{Parenthesis}

These have three uses in $\mathrm{H}$, namely: (a) to offer appositive sentences and phrases, and (b) to introduce metatextual expressions and stance. These functions are exemplified in the following instances, one per case:

(22) a. [...] Then take it off and straine out the Hopp, and seth the vinegre over the fire, [...], then take it off, and (as hott as you may suffer it) put one spoonefull in your mouth. (2)

b. [...] And when it is sodd

(as is before mencioned) you must burne it as you burne other wyne/. (51)

c. Pow = der made of the Stone of a Swallow; healeth (without doubt) those wich have the falling Evill./ (101)

The first example includes an apposition with information that is not necessary either to complete the remedy or to understand the message. We could, in fact, take this sense-unit out without affecting the meaning and the usefulness of the text. In the second example, the parentheses introduce a cross-reference sending the reader further back in the text to search for more information. Finally, the last instance offers an assertive expression showing the attitude of the writer in parentheses.

\subsection{The dash or hyphen}

The dash or hyphen can be of three types, curly, straight or double. There is no differentiation in the use of the first two. In fact, they also 
combine in a text in which they alternate in the same line. The main use of the simple hyphen is to complete the line visually, so that text space appears to be justified right and left. The hyphen also appears together with a virgule to fulfil the same function, as in example (23a), below. This function of the hyphen as a line filler is given in the index to join the entry and the page number. This use is included in example (23b).

(23) a. To make a Broth for one that is

weake./ $\quad \sim / \sim \sim \sim \sim \sim$

ffirst take a knockle of Veale, and boyle it in faire -

water, and putt to it parsley roots, [...] (44)
b. Pyles
168
Plaster
162 (xiii)

Another function of the hyphen is to signal compounds, as in seasinovey-grase, scurveygrasse, Marsh-Mallow, lambs-skynne (lambs includes the inflected genitive mark-s), and shellsnayle. The use of the double hyphen is to show word division in-between two lines, as in example (22C), section 4.5: Pow $=$ der.

\subsection{The virgule or slash}

This symbol has a main grammatical function in $\mathrm{H}$, and it is used to mark off sections, especially titles from the ingredients section, and the end of a text. Sometimes, it also appears in combination with the colon after separating index letters, or with the dash to justify blank spaces in lines. The following instance illustrates these uses of the virgule:

(24) A Medicine for the Megreme, very

excellent/

Take iiij or v: Nutmmeggs and pare and slyce them as you would pare and slyce ginger thynne, Then make ij Baggs of Lynnen Cloth of the length of your finger, and putt in the Nuttmeggs, Then take a quantitie of pure redd Rose water, and lay your baggs in the same water in a dish vpon a Chaffindish of Coles, and make them hott, and lay them to the Temples/ (140)

The virgule in this example signals the segmentation of the text into the title and the rest of the recipe. A conjunctive grammatical function of the slash has been attested once, given in (25) below, to introduce an additional authorial comment with respect to the preparation of the recipe. Arguably, this use of the slash has also some rhetorical overtones, since it highlights information that is not given but that is presumably known:

(25) Take also of good

Sugarcandy of like quantitie of a Wallnutt, all the -same being bruysed, take a pynt of stale Ale, and clarifie the same being bruysed and seeth all together / and -being well sodden, straine the same through a faire Cloth, and drinke thereof (58) 


\subsection{The perioslash}

The virgule may also combine with a period to form what Arakelian (1975: 619) calls the perioslash. The point can be either right or left flank.
Its main functions are to separate the title from the following stage and to indicate the end of the recipe, as in example (26), below:

(26) ffor the same./

Make a Glister of a handfull of Rewe sodden in Oyle

And Butter, and it taketh away the pain incontinent./ (47)

As pointed out in Calle-Martín and Miranda-García (2005: 37), these functions deployed in (26) represent a grammatical function of this symbol. These scholars argue that the main distinction between the perioslash and the slash in their corpus is that the former is disjunctive while the latter is conjunctive. In $\mathrm{H}$, both symbols are basically disjunctive. So much so that they alternate in the tasks of separating sections or thematic sense-units and indicating the end of the text, as shown in (27) and (28):

(27) A Medicine for the Stone/

Take a Pottle of Bathe water (if you can gett it)

if not, then other water, and a pottle of white wyne,

ijli of Sugarcandy, the luyce of one Pomgranate,

the Oyle of Cynamon halfe a Scruple, of gall-

stone of and Oxe oz, parsley one handfull, boyle all

these together by the space of two houres, and then straine it, and lett it stand vntill the nextday, and then drinke of it halfe a pynt at a tyme more or lesse./ (232)

(28) Against hoarfnes, to make open, and cleare the voyce./

Putt Musterseed in drye ffiggs, and give the Pati= ent them to eat in the Evening, It doth dissolue the grosse humours and openeth the slopping of the lights, and also the Conduits of breathing, and cleareth the voyce, where of wee have sopken more -at large pag where wee have entreated of Remedyes against the Cough and fflegme, and to open the Brest / (240)

\subsection{The paragraph mark}

This symbol only appears in marginal notes, and it is given alone or after a phrase or sentence. When the paragraph mark stands alone in the margins, its function is not always clear, as it seems to be indicating the ingredients stage, in the majority of the cases. In the first instance, we thought that the intention of the writer was to warn the non-specialist of a particularly tricky word, as in Stampe Smallage and putt it to Aquavita (7). However, this is not the case in many of the recipes marked in the margins with a paragraph mark. Thus, it seems to indicate the ingredients stage without any other intention.

There are cases in which this symbol accompanies a phrase or a sentence that summarises 
the contents of the recipe it accompanies. This usage helps the reader to identify the remedies easily, which is a highly-valued aspect in practical works such as this in which the search for therapeutic information should be carried out in the minimum amount of time. This stands for a structural use of the paragraph mark. The following marginal note is given near a recipe intended to cure several diseases: Oyntments for diuers causes and diseases 9 (155).

(29) a. ve. Wound fol. 251./

b. Of this matter how to heale a Broken Man or Rupture, wee shall speake hereafter, where wee Entreat of the Pultesses fol. 179/

\subsection{The asterisk}

As we have seen with the paragraph mark, the asterisk is given in the margins. Its function is to show a cross-referential device in the text. Asterisks in the margins enable the reader to find the related information on the pages in question quickly by spotting this symbol in the margins, and consequently not having the need to read the entire text. This is the only use of the symbol in $\mathrm{H}$.

\section{Conclusion}

In this paper, we have described and analysed the punctuation system in the text of Glasgow University Library, MS Hunter 93. This study should be seen as a contribution to filling the gap in punctuation studies on sixteenth century scientific texts. To carry out our analysis, we have followed a model based on that of Lucas (1971) for the study of punctuation symbols, which we have reworked to add the concept of generic stages. These stages mark the meaningful chunks of information into which texts divide. This division helps us to produce a first distinction with marks appearing at the division points between these sections, and we have categorised punctuation at this point as grammatical punctuation. This generic division of the text actually allows us to predict the point at which grammatical symbols would emerge. On a more notional level, punctuation given within stages tends to associate different parts of these stages. As for interpretative punctuation, $\mathrm{H}$ does not present many cases of this type. Very rarely do the authors use expository punctuation to clarify their texts; the elocutionary type is even rarer in $\mathrm{H}$. We have also detected cases of absence of punctuation symbols, showing both the inconsistency in their usage and the fall into disuse of some punctuation functions. These conclusions as to the punctuation of $\mathrm{H}$ are of special interest for critical editions of the text of $\mathrm{H}$, and are also applicable to other related contemporary texts.

\section{Bibliographic references}

Alonso-Almeida, Francisco, 1998-1999: "Gyf hyr this medycyn': Analysing the Middle English Medical Recipe Discourse", Revista de Lengua para Fines Específicos 5-6, 15-46.

Alonso-Almeida, Francisco, 2002: "Punctuation Practice in a Late Medieval English Medical Remedybook", Folia Linguistica Historica 22, (1-2), 207-232.

Arakelian, Paul G, 1975: "Punctuation in a Late Middle English Manuscript", Neuphilologische Mitteilungen 76, 614-624.

Biber, Douglas, 1988: Variation Across Speech and Writing, Cambridge: Cambridge University Press.

Calle-Martín, Javier, 2004: "Punctuation Practice in a $15^{\text {th }}$-century Arithmetical Treatise (MS Bodley 790)", Neuphilologische Mitteilungen 4, 407-422.

Calle-Martín, Javier \& Antonio Miranda-García, 2005: "Editing Middle English Punctuation. The Case of MS Egerton 2622 (ff. 136-165)", International Journal of English Studies 5, (2), 27-44. 
Calle-Martín, Javier \& Antonio Miranda-García, 2008: "The Punctuation System of Elizabethan Legal Documents: The Case of G.U.L. Hunter 3 (S.1.3)", The Review of English Studies 59, 356-378.

Carroll, Ruth, 1999: "The Middle English Recipes as a Text-type", Neuphilologische Mitteilungen $100,27-42$.

Carroll, Ruth, Risto Hiltunen, Matti Peikola, Janne Skaffari, Sanna-Kaisa Tanskanen, Ellen Valle \& Brita WarVIK, 2003: "Introduction" in Risto HILTUNEN \& Jane Skaffari (eds.): Discourse Perspectives on English: Medieval to Modern, Amsterdam and Philadelphia: John Benjamins, 1-12.

Clemens, Raymond \& Timothy Graham, 2007: Introduction to Manuscript Studies, Cornell: Cornell University Press.

EgGins, Suzanne, 1994: An Introduction to Systemic Functional Linguistics, London: Pinter.

Esteban-Segura, Laura, 2009: "Punctuation Practice in MS G.U.L. Hunter 509” in Javier E. Díaz-Vera \& Rosario Caballero-Rodriguez (eds.): Textual Healing. Studies in Medieval English Medical, Scientific and Technical Texts, Bern: Peter Lang, 93-107.

Fries, Charles C., 1925: "Shakespearean Punctuation", University of Michigan Studies in Shakespeare, Milton and Donne, New York and London: Ann Arbor, 67-86.

GöRLACH, Manfred, 1992: "Text-types and Language History: The Cookery Recipe" in Jan SVARTVIK \& H. WeKkER (eds.): History of Englishes. New Methods and Interpretations in Historical Linguistics, Berlin, New York: Mouton de Gruyter, 736-761.

Graham-White, Anthony, 1982: "Elizabethan Punctuation and the Actor: Grammer Gurton's Needle as a Case Study", Theatre Journal 34, (1), 96-106.

Hasan, Ruqaya, 1985: Linguistics, Language and
Verbal Art, Geelong, Vic: Deakin University Press.

Howard, Edwin J., 1930: "The Printer and Elizabethan Punctuation", Studies in Philology 27, 220-229.

Hunt, Tony, 1990: Popular Medicine in ThirteenthCentury England: Introduction and Texts, Cambridge: Cambridge University Press.

LUCAS, Peter J., 1971: "Sense-units and the Use of Punctuation-markers in John Capgrave's Chronicle”, Archivum Lingusticum (N. S.) 2, 1-24.

Marqués-Aguado, Teresa, 2009: "Punctuation Practice in the Antidotary in G.U.L. MSHunter 513 (ff. 37v - 96v)”, Miscelánea 39, 55-72.

MARQués-Aguado, Teresa, 2011: "Depunctuating the Middle English Benvenutus Grassus: The Cases of GUL, MSS Hunter 503 and 513" in Antonio Miranda-Garcia \& Santiago Gonzalez Fernandez-Corugedo (eds.): Benvenutus Grassus' On the Well-proven Art of the Eye (Practica Oculorum \& De Probatissima Arte Oculorum). Synoptic Edition and Philological Studies, Bern: Peter Lang, 55-74.

Martin, J. R., 1984: "Language, Genre and Register" in F. Christie (ed.): Children Writing: Reader, Geelong, Vic: Deakin University Press, 21-29.

McKenzie, D. F., 1959: "Shakespearean Punctuation-A New Beginning", The Review of English Studies 10, (40), 361-370.

OnG, Walter J., 1944: "Historical Backgrounds of Elizabethan and Jacobean Punctuation Theory", PMLA 59, (2), 349-360.

Ortega-Barrera, Ivalla, 2005: Edición del recetario 'Booke of soueraigne Medicines' de John de Feckenham según el manuscrito Hunter 93 (T.4.10.), Biblioteca Universitaria de Glasgow, con descripción, notas y glosario. Unpublished PhD, Las Palmas de Gran Canaria: University of Las Palmas de Gran Canaria.

Ortega-Barrera, Ivalla, 2009: "The Advice Genre 
(1400-1599). Genre and Text Type Conventions", Studia Anglica Posnaniensia 45, (2), 39-58.

Parkes, Malcolm B., 1978: "Punctuation, or Pause and Effect" in James J. Murphy (ed.): Medieval Eloquence. Studies in the Theory and Practice of Medieval Rhetoric, Berkeley, Los Angeles, London: University of California Press, 127-142.

PetTl, Anthony G., 1977: English Literary Hands from Chaucer to Dryden, London: E. Arnold.

Salmon, Vivian, 1962: "Early Seventeenth-century Punctuation as a Guide to Sentence Structure", Review of English Studies 13 (52), 347-360.

Salmon, Vivian, 1988: "English Punctuation Theory 1500-1800”, Anglia 106, 285-314.

StannaRd, Jerry, 1982: "Rezeptliteratur as Fachliteratur. Studies on Mediaeval Fachliteratur" in WiIliam Eamon (ed.): Scripta: Mediaeval and Renaissance Texts and Studies 6, Brussels, 59-73.

TAavitsainen, Irma, 2001a: "Changing Conventions of Writing: the Dynamics of Genres, Text Types, and Text Traditions", European Journal of English Studies 5 (2), 139-150.

TAAVITSAINEN, Irma, 2001b: "Middle English Recipes: Genre Characteristics, Text Type Features and Underlying Traditions of Writing", Journal of Historical Pragmatics 2, (1), 85-113.

WerLICH, E., 1976: A Text Grammar of English, Heidelberg: Quelle and Meyer. 